Article

\title{
A Preliminary Study on Connectivity and Perceived Values of Community Green Spaces
}

\author{
Sohyun Park \\ Department of Landscape Architecture, Texas Tech University, 2907 15th Street, Lubbock, TX 79409-2121, USA; \\ sohyun.park@ttu.edu; Tel.: +1-806-834-1710 \\ Academic Editor: Audrey L. Mayer
}

Received: 22 January 2017; Accepted: 25 April 2017; Published: 27 April 2017

\begin{abstract}
Green spaces in residential communities are important yet understudied features of the urban ecological system. While large urban parks and remnant wildlands in urban areas tend to receive public attention from conservation and management perspectives, less is known about the importance of spatial and ecological characteristics of the community-scale green space. This study investigates natural elements in four planned communities in the Phoenix metropolitan area, Arizona; two of which represent conventional types of neighborhoods and two which exemplify community development type with a proclaimed vision of sustainability. These distinct types of communities, which illustrate variations in age, location, open space type, and a cross-section of housing density, are compared with regard to landscape connectivity as a means of gauging the ecological condition for community sustainability. Using Geographical Information Systems and landscape connectivity indices, a community's green space features were examined including size, physical connectedness, and ecological potential. Furthermore, a questionnaire survey was designed and implemented to examine the perceptional differences between the two types of community residents. The findings demonstrate that the green spaces in conventional communities are more physically connected than their counterparts, but the naturalness and ecological qualities manifested in the amount of the land that may serve as potential urban desert habitats were higher in the sustainable communities. The results of the survey indicated that the respondents inhabiting sustainable communities possess a higher level of satisfaction than the people in conventional types of communities. This is due mainly to the amount of easy access to, and the perceived ecological values of the green spaces in their neighborhoods and surrounding areas. The study concludes that careful community design with ecological consideration can help create sustainable communities which can benefit both site-scale ecosystems and perceived human well-being.
\end{abstract}

Keywords: ecological sustainability; landscape connectivity; green spaces; resident perception; master-planned community; Phoenix (Arizona)

\section{Introduction}

Green spaces in residential communities are important yet understudied features of the urban ecological system. While there are numerous studies dealing with urban green spaces in the context of human dimensions [1-3], they usually focus on public recreational lands (e.g., county or city parks) with limited consideration of the extended impacts and benefits of the ecological aspects of the green spaces within residential communities. Other examples studying green spaces in residential areas employ a single facet of characteristics and the roles that they hold, such as human health [4-7], environmental justice [8], bird biodiversity [9], and neighborhood socioeconomic status as a predictor of the perennial landscape vegetation [10]. Although these aspects are all important to secure green spaces in human-dominated landscape, the general views of residential green spaces are to some extent fragmentary and non-connective. 
Given the fact that master-planned communities are becoming a prominent type of modern community development in large metropolitan areas, and considering the lot size of contemporary housing units has increasingly been larger, there are growing opportunities to offset the challenges resulting from large-scale development and the lack of quality green spaces in residential communities. One example of this is designing with nature in the form of green space systems for communal use; such as community parks, natural trails, and shared adjacent natural reserves organically connected with the common residential landscape features such as front and back yards and manicured streetscapes. Arguably, one such practical approach would rest on how these natural features are placed, arranged, and connected in the landscape of human communities, which in turn influences not only the residents' physical activities and satisfaction but the micro- and meso-scale ecological flows and processes as well. Nonetheless, few physical design guidelines relating to green space form and service provision are found in community development and planning practices.

However, a theoretical approach rooted in urban and landscape ecology supports the idea of securing small-scale ecosystems as part of community-scale green space networks. A body of literature has also tackled the issue of increasing ecological quality and sustainability in the context of urbanization and landscape pattern changes resulting from anthropogenic activities [11-13]. With the increasing acceptance of the notion of 'cities as ecosystems' [11,14], it is worthwhile to revisit contemporary community landscape features to unveil the relationship between green space configurations and ecological quality as a way to find less disturbing patterns in site ecology and to weave the green 'granules' together within a broader urban ecosystem. This perspective questions of how green spaces in human communities can, and should, be planned, designed, and shaped to promote human-nature interaction and an ecologically sustainable community.

Although the term "sustainable communities" has various definitions depending on the goals and principles of the community development, it commonly indicates that the community is planned, built, and managed to promote sustainable living for existing and future residents. In an ideal situation, the economic, social, and environmental components of sustainability should be integrated into the community planning process, plan reports, and management practices in a balanced manner. While the economic sustainability tends to be sought in establishing urban infrastructure, utility services, resource investment, and economic self-sufficiency through local ownership (UK Government Web, [15]), social sustainability is examined in terms of social equity, inclusion, safety, and well-being of community residents and also constitutes political empowerment and community bonds ([16], Sustainable Communities Task, [17]). Sustainable communities with an emphasis on environmental components tend to employ renewable energy, sustainable water use, recycling measures, and the preservation and improvements of green spaces and natural resources (Sustainable Communities Task, [17]). These communities are sensitive to their environment and are also referred to as "green communities" or "eco-communities". In real world practices, however, new residential communities claiming to stand for sustainability either do not support the balance of sustainability components or use it more as a symbolic or marketing term [18]. More so the ecological aspects of sustainability (e.g., human-nature interaction, green space connectivity, urban habitats, natural process, and productivity) have rarely been addressed in community development processes; presumably due to the conventional emphasis on human functions within the residential communities.

This study examines four large-scale communities in the Phoenix, Arizona metropolitan area; two representing conventional types of neighborhoods and two exemplifying communities claiming sustainability as a vision for their communities. The conventional communities chosen for comparison are differentiated from sustainable communities in that they have a lower degree of planning and no articulation of the language of sustainability either in their plan documents or planning processes. With a focus on physio-ecological characteristics and residents' perspectives on the green spaces in each community, the study aims to: (1) quantify and compare green space connectivity between conventional and sustainable communities, and (2) understand residents' uses, perceptions, values, and satisfaction with the green spaces within these two types of communities. To achieve these objectives, the study 
attempts to answer the following questions: (1) What are the landscape features characterizing modern residential communities?; (2) How do people use and perceive their residential green spaces?; (3) Are there any notable differences in landscape connectivity measures and human's perception depending on the different type of community development?; and (4) What are the implications in community development and urban design practices seeking ecological sustainability?

\section{Materials and Methods}

\subsection{Case Study: Two Types of Communities}

Four master-planned communities in the Phoenix metropolitan area were chosen, two of which represent conventional types of communities (C1: Dobson Ranch; C2: Superstition Spring) and two representing communities where the sustainability vision is anticipated in the community plans (S1: Verrado; C2: Las Sendas). These distinct type of communities, which capture variations in age, location, open space type, and a cross-section of housing density, were selected to compare landscape connectivity as a means of gauging the ecological sustainability of the community (Table 1). Dobson Ranch is comprised of five census tracks (4222.04, 4222.05, 4222.12, 4222.21, and 4222.22) with 14,538 residents, while Superstition Vistas includes three census tracks (4226.37, 4226.38 and 4226.39) in which 11,079 people reside. The Verrado community has one census track (506.06) with 6779 people living in the community, while Las Sendas is comprised of two census tracks (4201.07 and 4201.009) with the total population of 10,394. Dobson Ranch (C1) and Superstition Spring (C2) are located relatively closer to the urban center with an average of $29.5 \mathrm{~km}(18.3 \mathrm{mi})$ from the downtown Phoenix; whereas Verrado (S1) and Las Sendas (S2) are situated along the urban periphery with an average of $48.5 \mathrm{~km}$ (30.1 mi) from the urban core (Figure 1). The community selection was made after consulting with local urban planners and designers.

Table 1. Basic profile of the four selected communities (US Census 2010).

\begin{tabular}{ccccc}
\hline Community Type & \multicolumn{2}{c}{ Conventional Community } & \multicolumn{2}{c}{ Sustainable Community } \\
\hline Community Name & Dobson Ranch & Superstition Spring & Verrado (S1) & Las Sendas (S2) \\
Year built & (C1) & (C2) & 2004 & 2004 \\
Area $\left(\mathrm{km}^{2}\right)$ & 1973 & 1995 & 22,792 & 9430 \\
Distance from urban center $(\mathrm{km})$ & 9187 & 9011 & 42 & 55 \\
Number of residents & 21 & 38 & 6799 & 10,394 \\
Housing type & 14,538 & 11,079 & $\mathrm{SF} / \mathrm{MF}^{1}$ & $\mathrm{SF}^{1}$ \\
Existence of HOA & $\mathrm{SF} / \mathrm{MF}^{1}$ & $\mathrm{SF} / \mathrm{MF}^{1}$ & Yes & Yes $^{1}$ \\
\hline
\end{tabular}

${ }^{1} \mathrm{SF}$ and MF indicates single-family and multi-family housing, respectively. 


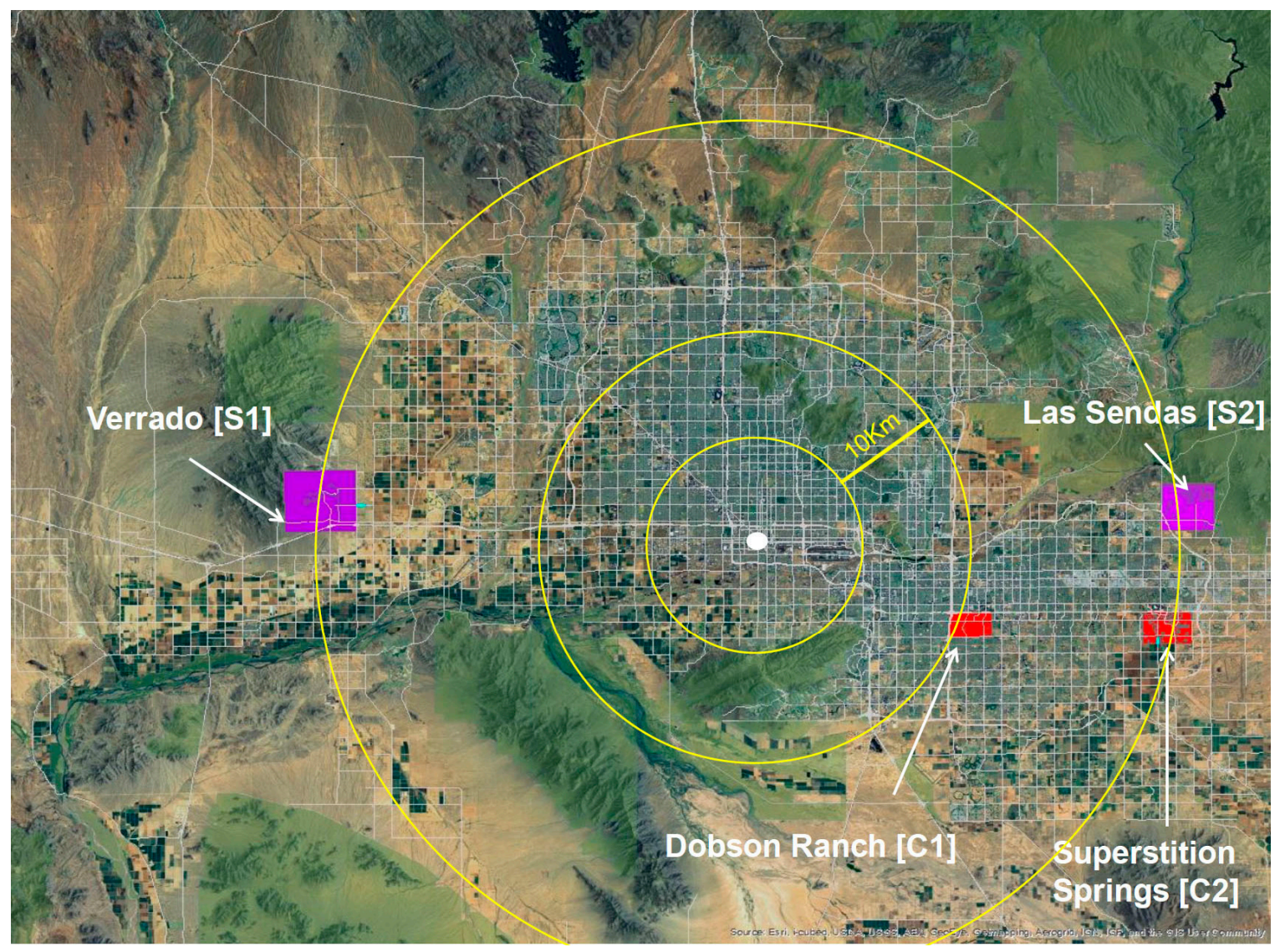

Figure 1. Location of the selected communities (red: conventional communities; purple: sustainable communities).

\subsection{Measures of Landscape Connectivity}

To understand the spatial pattern of green spaces in the chosen communities, two sets of connectivity measures were employed. The first tool relates to the degree of physical connectedness of green spaces and the second tool identifies the areas that have urban desert habitat potential. On the one hand, the Structural Connectivity Index (SCI), a measure to quantify landscape pattern, was used for each community using FRAGSTATS (version 4.2.1, the University of Massachusetts Landscape Ecology Lab: Amherst, MA, USA, 2012), a landscape pattern analysis software. Based on the physical composition and arrangement of the natural elements and designed green space features, a numeric value of SCI represents the degree of physical connectedness of green spaces in each community. To identify the green spaces that need to be considered for the analysis, satellite images and land use maps were used. Additionally, scanned microfilms that contain the information of land use and zoning changes were used as a supplementary material, in particular for the selected conventional communities to understand land conversion from green spaces to non-natural land use. On the other hand, predeveloped maps resulting from the Ecological Connectivity Index (ECI)-based connectivity modeling were utilized to identify the land parcels with higher ecological values (For details, see [19]). The ECI translates continuous surface values from an ecological perspective into a community's potential for sustainable landscapes.

\subsection{Residents' Perception Survey}

With the aim of understanding residents' preferences, personal values, and environmental priorities regarding their community green spaces, a questionnaire survey with a series of questions was designed, formulated, and distributed to a random sample of the residents in each community. 
The survey consisted of 20 questions in four categories including perception, values, preferences, and satisfaction, while requiring various response formats such as multiple answers, ranking, scale, and open-ended questions that were supplemented by a subsequent short-interview.

The questionnaire started with the general questions about the use and experience of the green spaces in the communities including: Which green space features does your community have? Which green space features do you use the most? For what purpose do you use the green space features the most? How easily can you get access to the nearest natural reserves from your community? If you can think of any unique or valuable natural characteristics in or around your community, what is it and why? In your community, to what extent are you in contact with nature and wild animals? In the perception category, the following questions were asked: Do you think that your community is ecologically sustainable or environmentally friendly and sustainable? In your opinion, does the existence of natural features contribute to social cohesion in your community? How much do you think the existence of neighborhood green spaces contributes to your quality of life? To identify how people value the roles of green spaces in community, the following questions were asked: How strongly do you agree or disagree with the following statements-Neighborhood green spaces can positively influence the health of residents; Neighborhood green spaces serve as habitats for local wildlife; Neighborhood green spaces contribute to the quality of life of residents; Neighborhood green spaces can contribute to the ecology of the broader environment; Neighborhood green spaces can contribute to the increase in property values; Green spaces within neighborhoods can contribute to a sense of belonging towards the community. For residents' level of satisfaction with their green spaces, the following questions were asked: Are you satisfied with the amount of the green spaces in your community? Are you satisfied with the greenness of the green spaces in your community? Are you satisfied with the overall quality of the green spaces in your community? Are you satisfied with the maintenance of the green spaces in your community? The questions about residents' preferences included: If your community is allowed to build a natural green space in your community, what would you like to add the most? Would you like to see small mammals in your community if they are not harmful to you and your property? In the past five years, have you ever been involved in nature activities such as birding clubs or a trees and shade program while you are living in the community? The questionnaire ended with an open question asking: Do you have any comments about the structure, arrangement, and nature of green spaces in your community and broader surrounding areas?

The initial survey was made using an online survey tool, SurveyMonkey ${ }^{\circledR}$ (SurveyMoneky Inc.: San Meteo, CA, USA, 2012), from August to October in 2012, and the survey link was posted on community centers' websites and social media pages. The survey was then followed by face-to-face surveys mostly during the weekends from October 2012 through April 2013. The face-to-face survey was performed primarily for those communities where an online survey was not allowed or the response rate was extremely low. It served as a complement to diminish coverage error associated with the systematic exclusion of eligible people, especially those who do not have a personal computer and/or access to internet. The respondents were sought mainly at community centers and neighborhood parks. Using a non-probability sampling technique, a total of 122 residents (58 individuals from conventional communities and 63 from sustainable communities) responded to the survey questions from the target population (the number of residents living in the four communities) of 31,868 (as of 2013).

\section{Results}

\subsection{Physioecological Green Space Quality}

The landscape of Dobson Ranch (C1) includes eight artificial lakes adjoined by greenbelts, golf courses, and linear landscapes. The Superstition Spring (C2) landscape demonstrates a geometric form of several neighborhood parks along the engineered stream channels running across the area. Golf courses are a common feature to all chosen communities except Superstition Spring (C2) which 
instead possesses a small tract of urban agricultural land in the southern part of the area. The Dobson Ranch (C1) and Superstition Spring (C2) communities are relatively flat in elevation and do not have sizable natural lands, while the other group of communities illustrates varying degrees of topography with a close proximity to urban natural reserves, such as the White Tank mountain near Verado (S1) and the Boulder mountain, the Sendas mountain, and the Tonto National Forest surrounding Las Sendas (S2) (Figure 2).

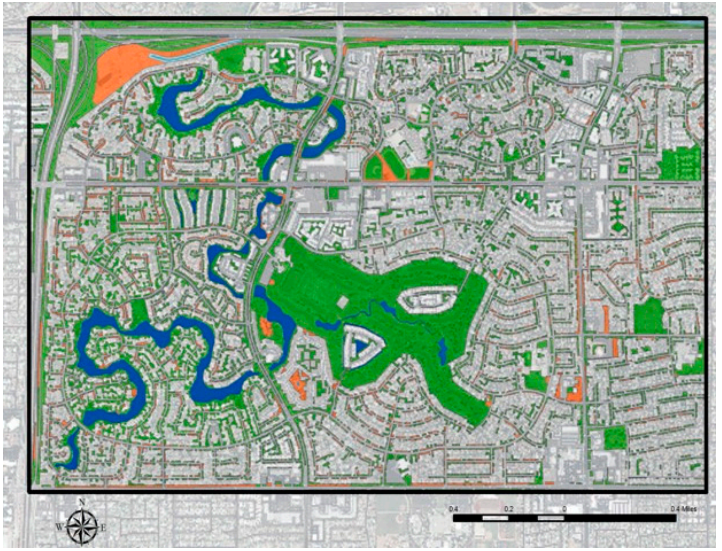

(a)

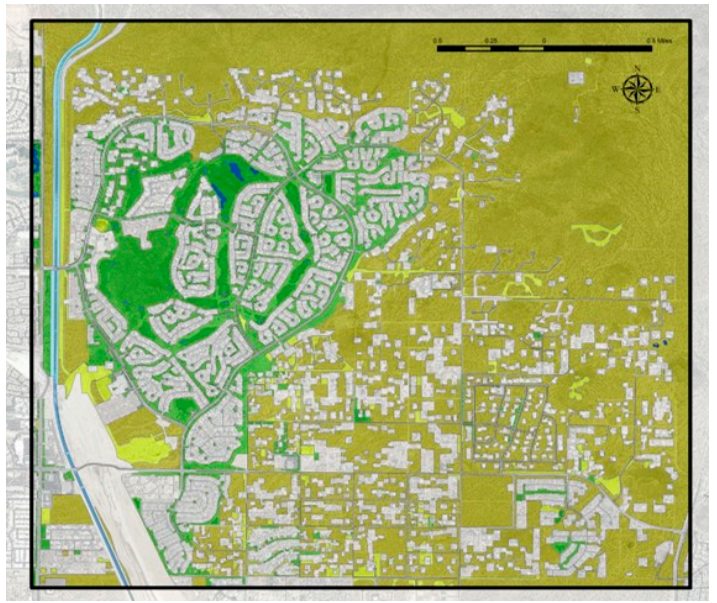

(c)

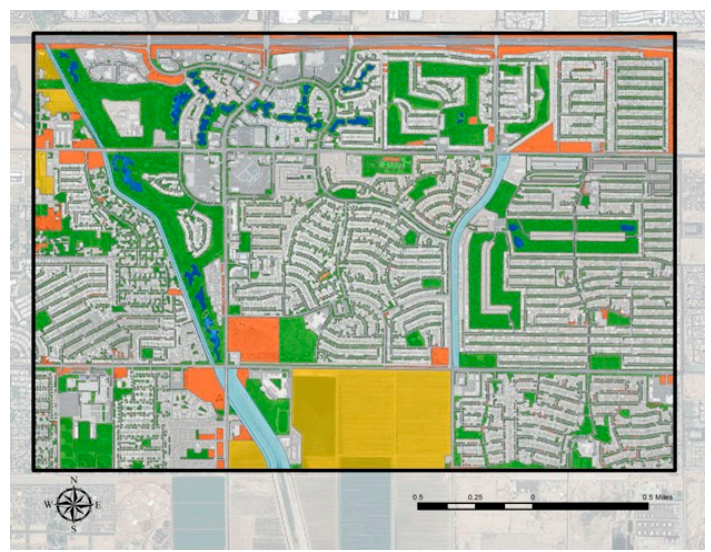

(b)

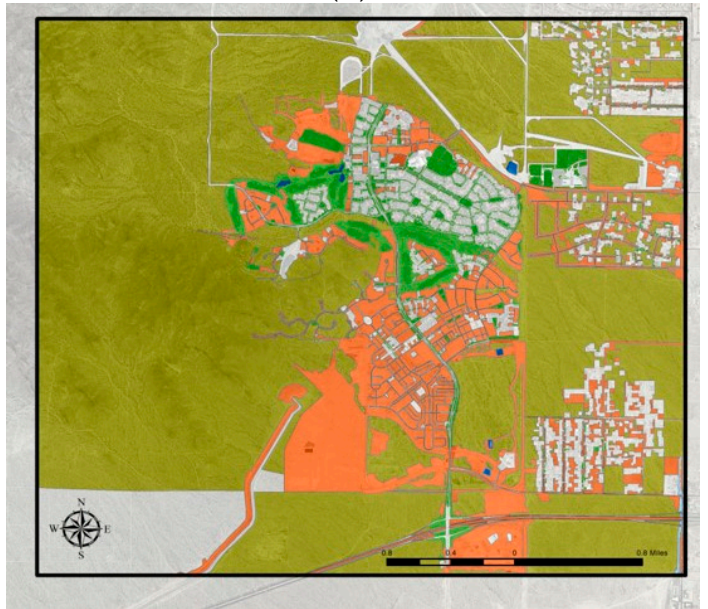

(d)

Figure 2. Physical properties of green spaces in the selected communities. Green: urban green spaces; Yellow: urban agriculture; Orange: vacant areas (areas not designated for a specific land use or areas for future development); Brown: natural areas. (a) Dobson Ranch; (b) Superstition Springs; (c) Verrado; and (d) Las Sendas.

\subsection{Structural and Ecological Connectivity}

The structural connectivity values of the conventional communities showed 0.075 for Dobson Ranch and 0.035 for Superstition Spring, which is slightly higher than those of the sustainable communities, 0.043 for Verrado and 0.024 for Las Sendas. Higher structural connectivity in the conventional communities presumably results from long-established green space systems including old and matured trees and the existence of water features that are linked with other natural elements within the community boundaries (Figure 3). On the other hand, the distribution of higher ECI (Ecological Connectivity Index) areas are greater in sustainable communities compared to the conventional ones. There are some spatial variables that might influence the results mainly related to the locational context, size, and dimension of natural elements, as well as, the distance to the adjacent natural sources (Figure 4). 
Structural Connectivity Index: 0.075

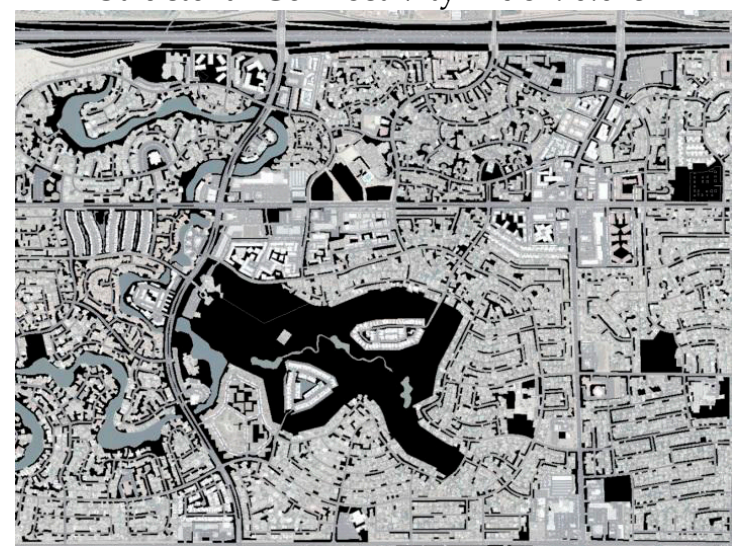

(a)

Structural Connectivity Index: 0.043

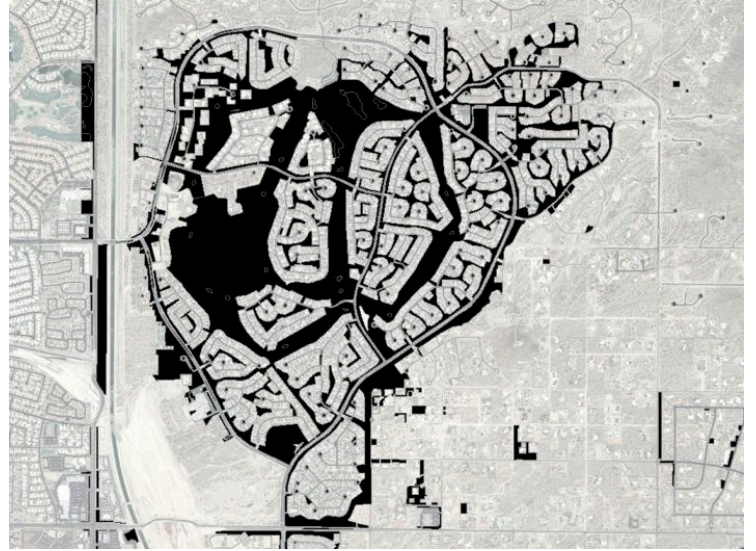

(c)
Structural Connectivity Index: 0.035

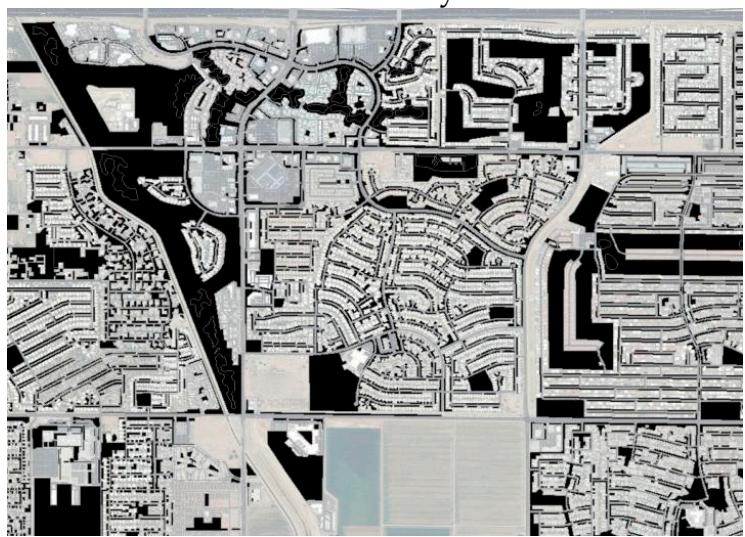

(b)

Structural Connectivity Index: 0.024

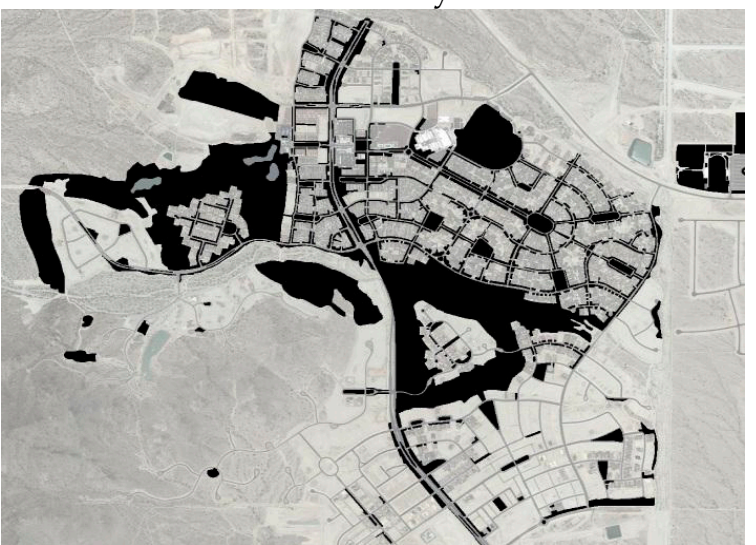

(d)

Figure 3. Structural connectivity of green spaces in the selected communities. (a) Dobson Ranch; (b) Superstition Springs; (c) Verrado; and (d) Las Sendas.

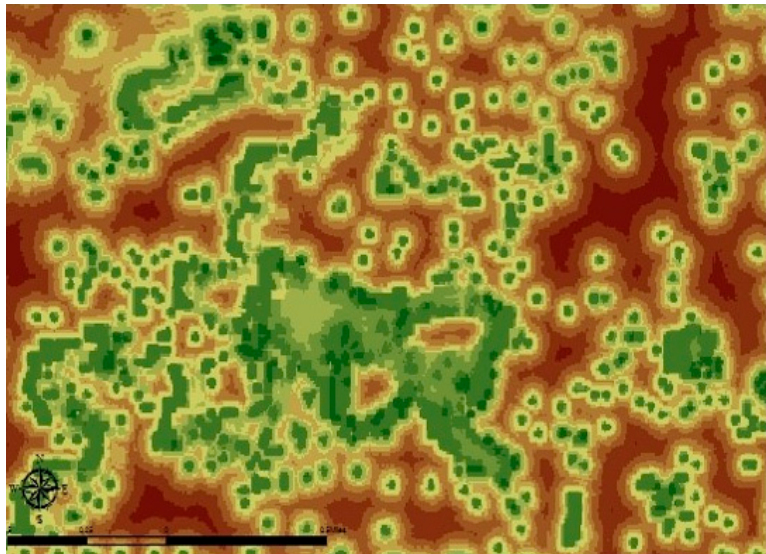

(a)

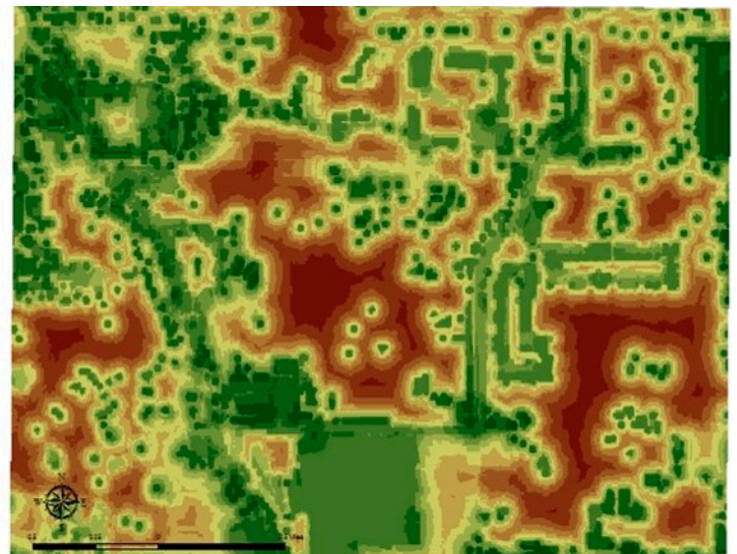

(b)

Figure 4. Cont. 


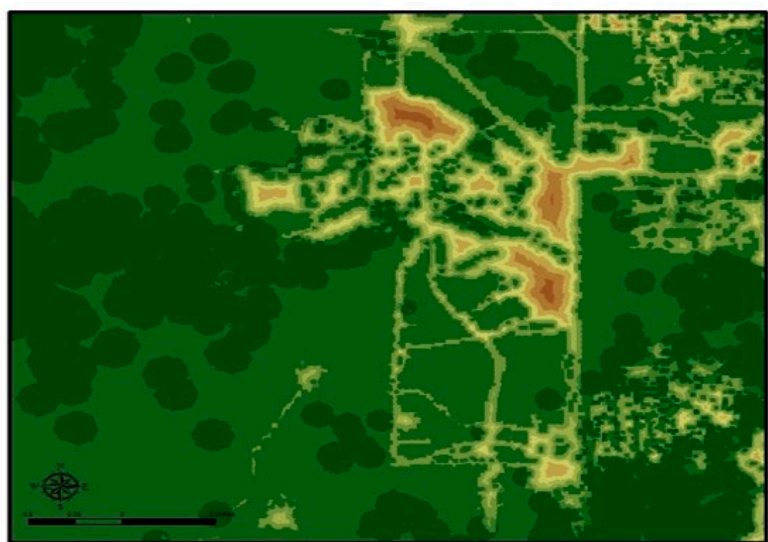

(c)

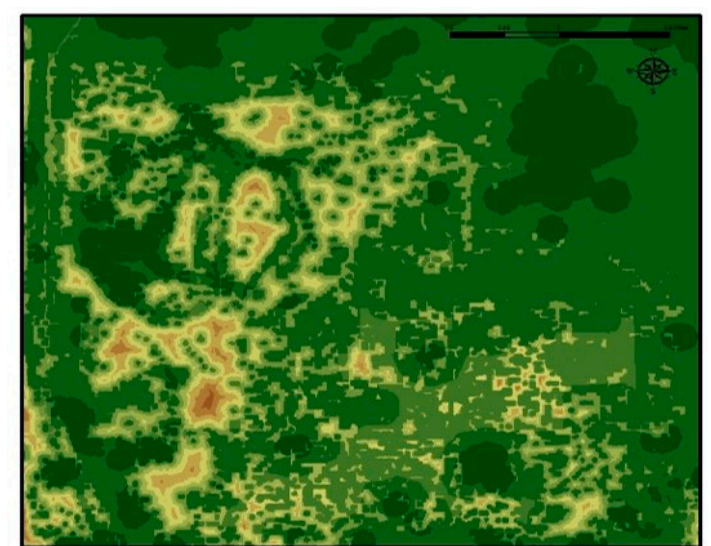

(d)

Figure 4. Ecological connectivity areas in the selected communities (brown: low connectivity; green: high connectivity). (a) Dobson Ranch; (b) Superstition Springs; (c) Verrado; and (d) Las Sendas.

\subsection{Residents' Survey}

A summary of the main findings from the residents' survey shows that there is community appreciation of green spaces with ecological, natural, and aesthetic values regardless of the development type. However, it is obvious that a higher degree of satisfaction and coherent linkages to other values of green spaces are shown in the communities where sustainability was envisioned in the development process. The results reinforce the importance of surrounding nature and access to large ecological sources for the residents' quality of life and socio-economic values. The following sections describe the primary responses for the questions in three arenas of residents' perception, satisfaction, and preferences/values associated with natural features of their communities, as well as demographic characteristics of the respondents.

\subsubsection{Characteristics of Respondents}

The demographic characteristics of the residents such as age, gender, race, education, and income levels are shown in Figures 5-9. More than half of the respondents from the conventional communities were middle-aged individuals, while the respondents of the sustainable communities showed a bit wider age range with nearly half of the residents under 39 years old (Figure 5). Although the respondents of the survey were mostly female and white, the sustainable communities' respondents were slightly more diverse in terms of race (Figures 6 and 7). As for the socioeconomic status of the survey respondents, higher levels of education and income were characteristic of those in sustainable communities (Figures 8 and 9).
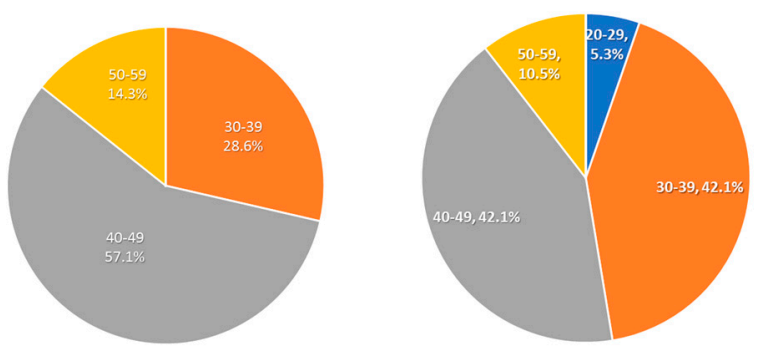

Figure 5. Age range of the residents ((left): conventional communities, (right): sustainable communities). 

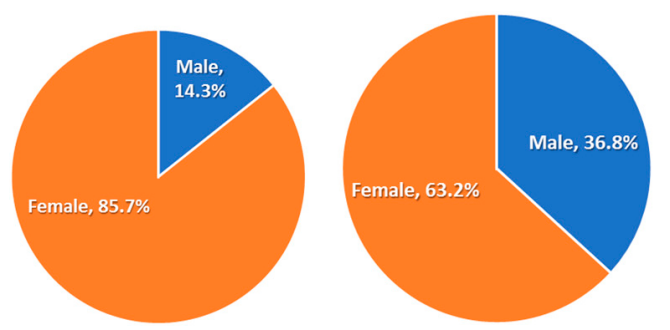

Figure 6. Gender distribution of the residents ((left): conventional communities, (right): sustainable communities).
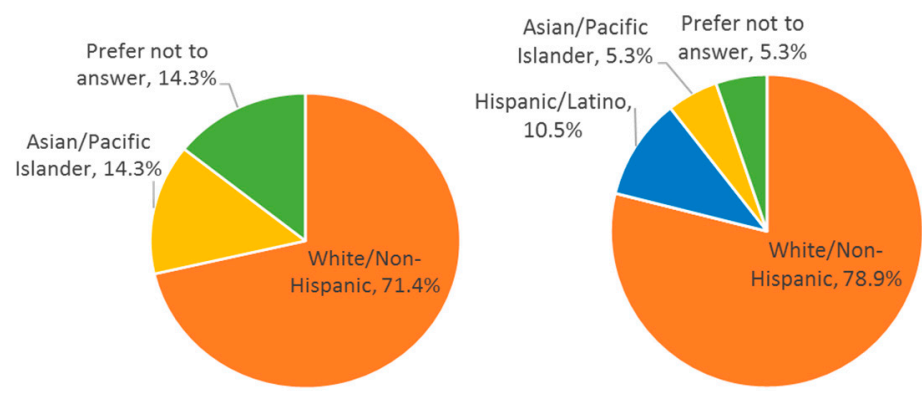

Figure 7. Race distribution of the residents ((left): conventional communities, (right): sustainable communities).

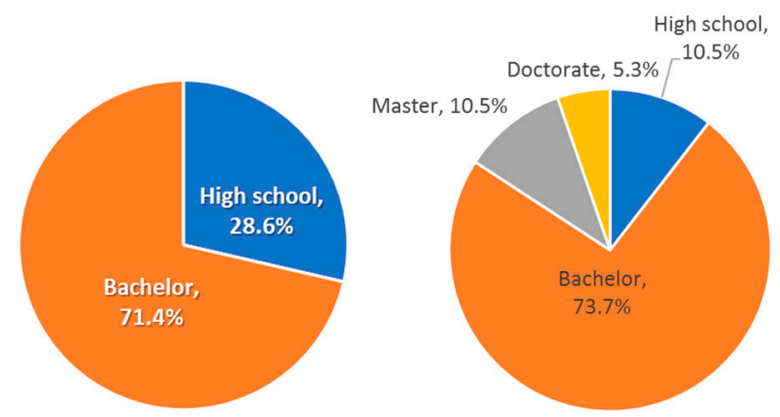

Figure 8. Education level (the highest degree earned) of the residents ((left): conventional communities, (right): sustainable communities).
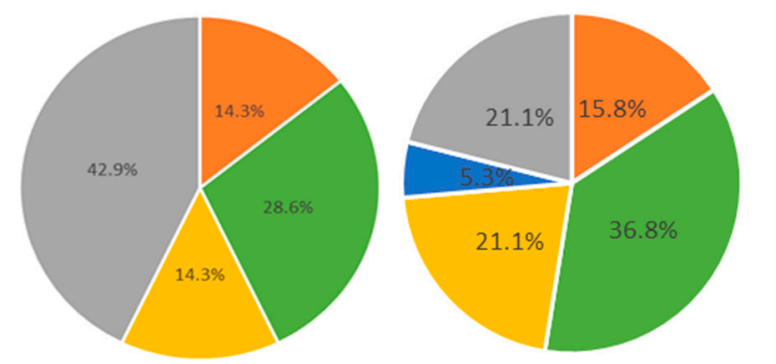

- US\$30,000 - US\$60,000

- US\$60,000 - US\$100,000

- US\$100,000- US\$200,000

- More than US\$200,000

- Prefer not to answer

Figure 9. Income level of the residents ((left): conventional communities, (right): sustainable communities).

With regard to residence period and home ownership of the respondents (Figures 10 and 11), a majority of the respondents were home owners (86 percent for conventional communities and 74 percent for sustainable communities) and had lived in their respective communities for at least three years (71 percent for conventional communities and 53 percent for sustainable communities). 

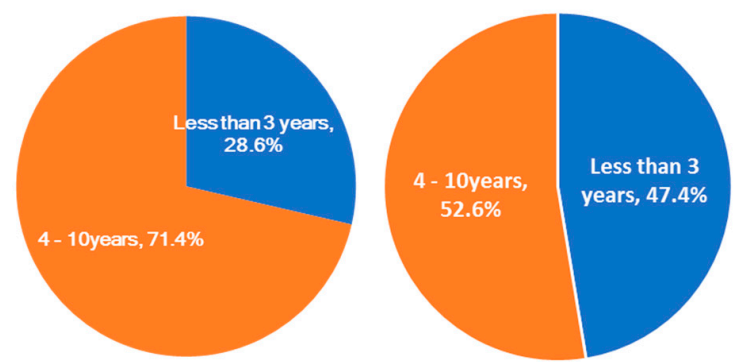

Figure 10. Years of residence ((left): conventional communities, (right): sustainable communities).
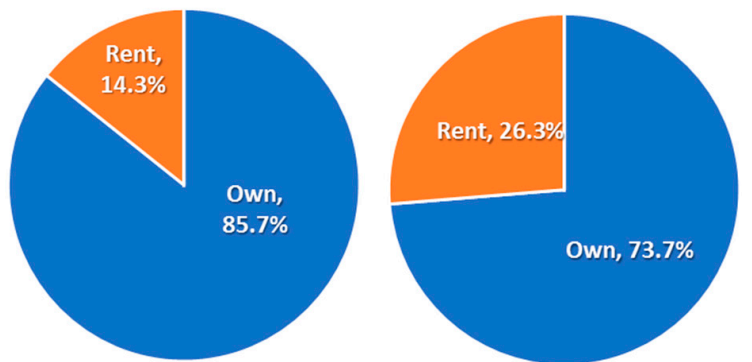

Figure 11. Home ownership ((left): conventional communities, (right): sustainable communities).

\subsubsection{Residents' Perception}

\section{- Uses and Purposes}

The residents in conventional communities used private green spaces most, such as front and back yards, followed by neighborhood parks. The landscapes most frequently used by the people in sustainable communities appeared to be community parks, mountain parks, and natural trails, which can be categorized as shared or communal spaces (Figure 12). While the respondents in conventional communities used the green spaces mainly for sports/recreation and relaxation purposes, the landscape experiences with their counterparts were more evident in nature-related activities such as hiking and contact with wildlife. What is common to both types of communities is their primary usage of the landscape for playing with children, which reflects their desire for spaces suitable for families (Figure 13).

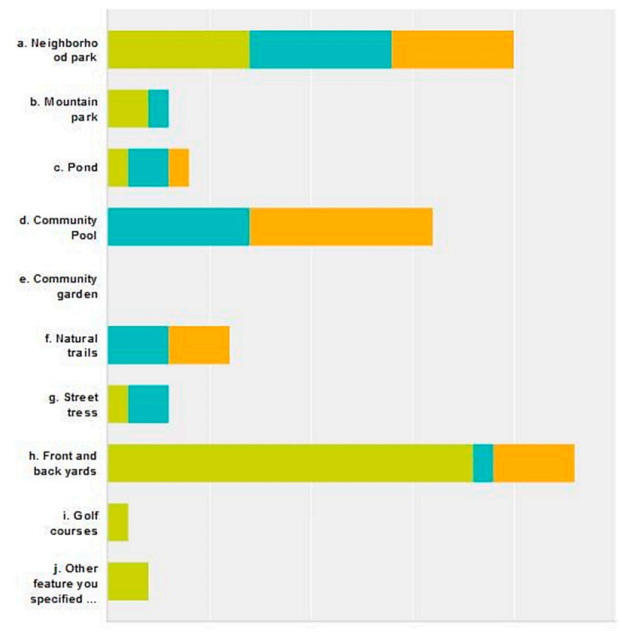

(a)

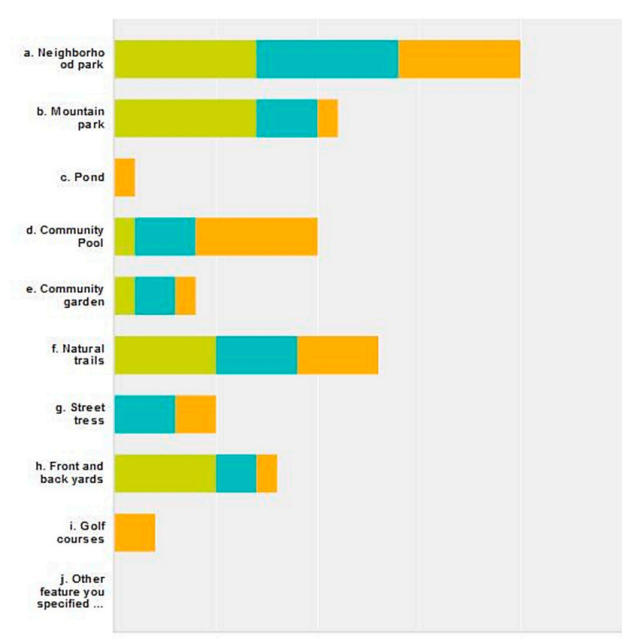

(b)

Figure 12. User preference ranking (green: 1st choice, blue: 2nd choice, orange 3rd choice) (a) Conventional community (b) Sustainable community. 


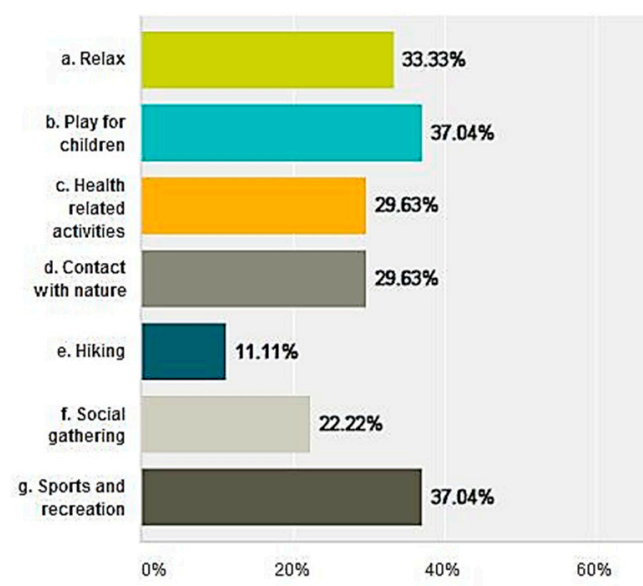

(a)

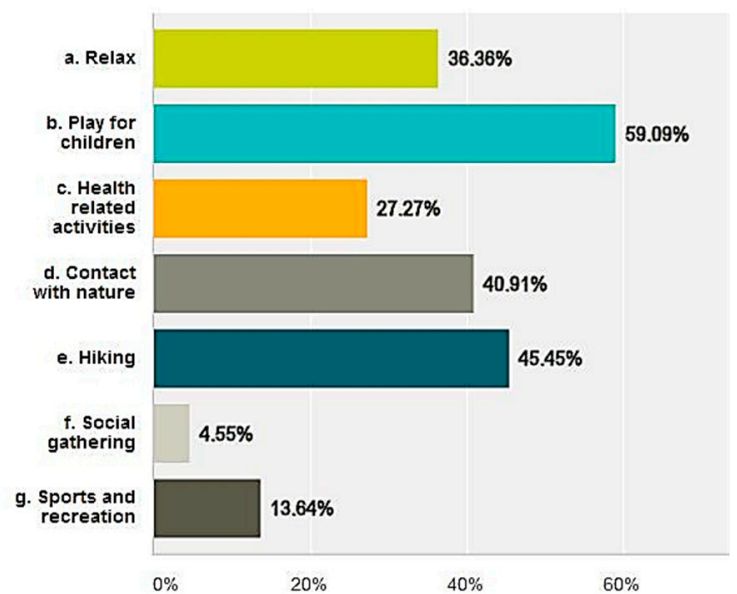

(b)

Figure 13. Purposes of landscape use (a) Conventional community (b) Sustainable community.

- Perceived Accessibility to Urban Nature and Sustainability

With regard to the perceived accessibility to the nearest urban nature, approximately 60 percent (C1 and C2) and 95 percent (S1 and S2) of the respondents in each type of community indicated that there is easy access (Figure 14). The perceived preference for the opportunity of wildlife encounter indicated that approximately 94 percent of the people would like to see small wild animals in their communities. Regarding the question about their experiences with wildlife in these locales, 45 percent of the conventional community respondents answered that they have a high chance of observing small urban species such as raccoons, lizards, squirrels, and rabbits. Many of them mentioned water birds such as ducks, cranes, geese, and great blue herons (presumably resulting from the existence of the lakes within the communities). In the sustainable communities, $87 \%$ of respondents listed the names of species that they often encounter, mostly the mid-sized mammals that are rarely observed in urban areas, including coyote, mule, deer, and bobcat. As such, perceived ecological sustainability was higher in sustainable communities (92\%) compared to the other group (62\%) where one fourth of the total respondents viewed their community as far from being environmentally friendly or ecologically sustainable (Figure 15).

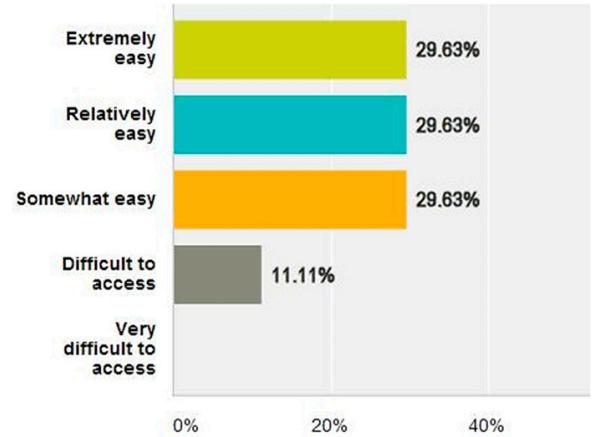

(a)

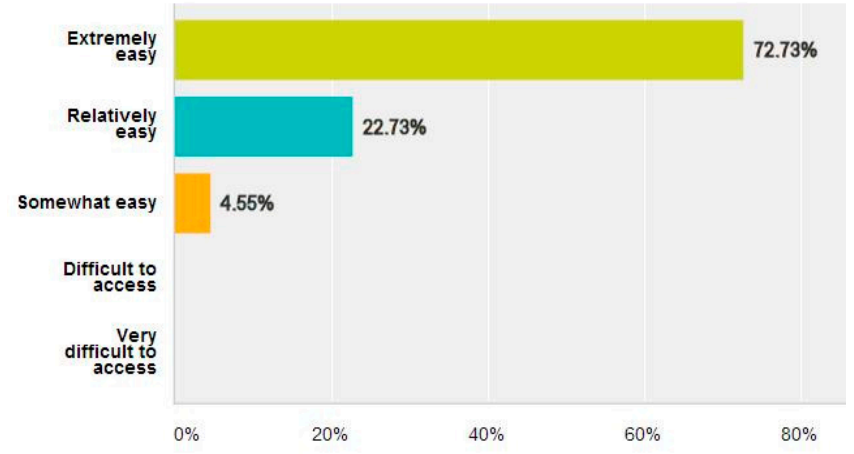

(b)

Figure 14. Perceived accessibility to adjacent natural areas (a) Conventional community (b) Sustainable community. 


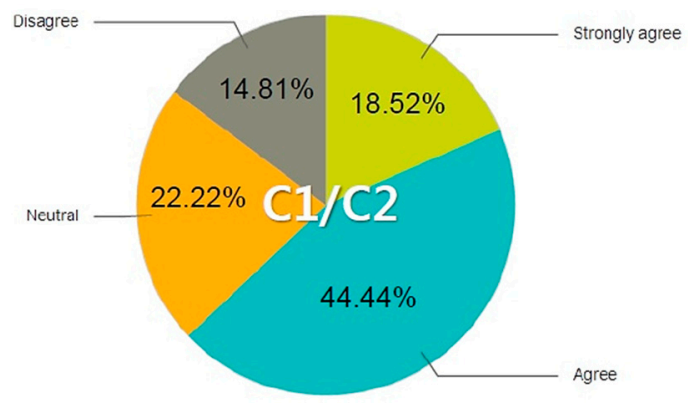

(a)

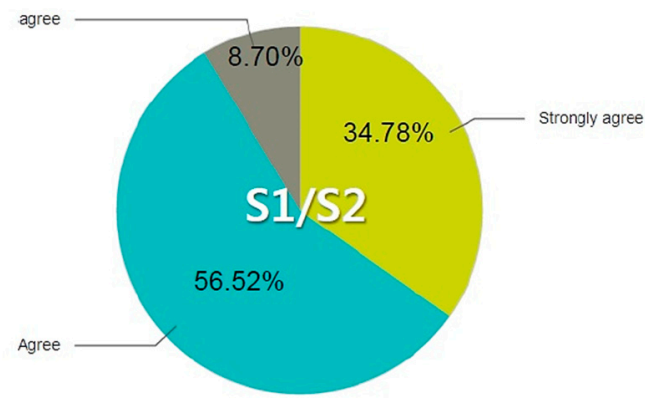

(b)

Figure 15. Perceived sustainability between the two types of community (a) Conventional community (b) Sustainable community.

\subsubsection{Resident's Satisfaction}

The overall quality of green spaces was highly appreciated by the respondents from the sustainable communities (100 percent for satisfaction). By contrast, 3.7 percent of respondents from the conventional communities expressed extreme dissatisfaction over their green spaces, although about 67 percent was still satisfied with the landscape quality in their communities. The lack of satisfaction is attributed to the amount and management of green spaces rather than greenness (Figure 16).

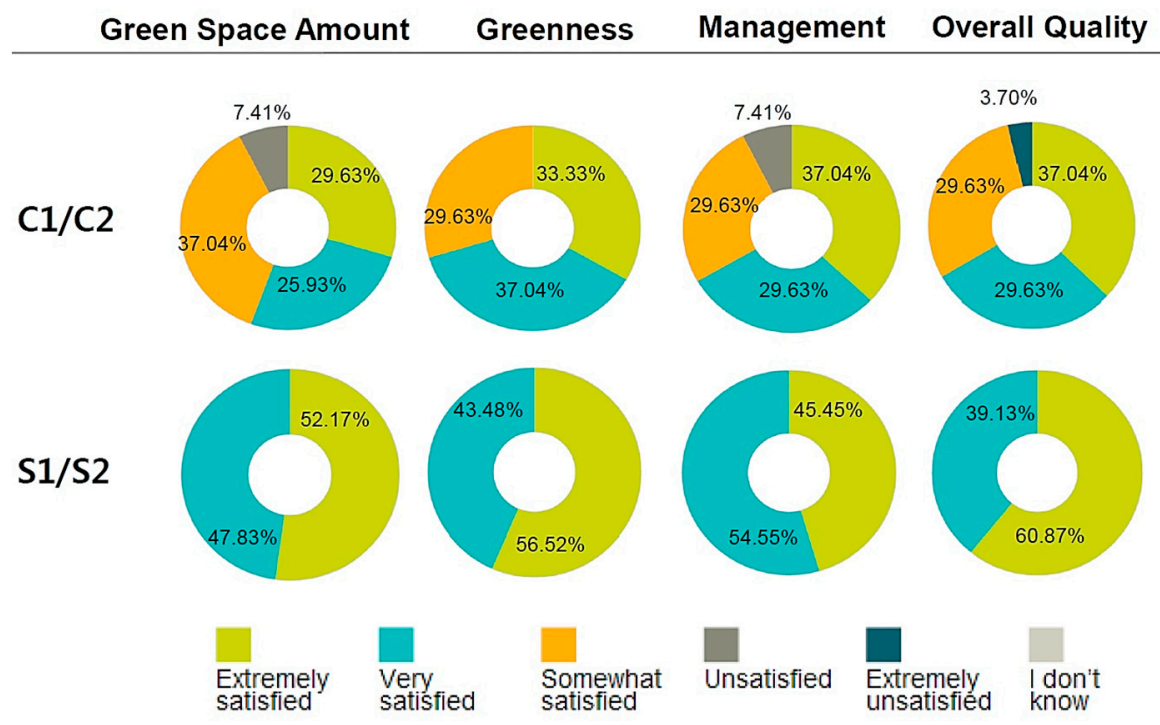

Figure 16. Resident's satisfaction for green space amount, greenness, management, and overall quality.

\subsubsection{Values and Preferences}

- Values of Community Green Spaces

A majority of respondents recognized the potential roles and values of the green spaces in human communities. To the question of the extent of agreement to the statements relating to the roles and values of green spaces, most of the respondents strongly agreed that green spaces influence human health, support local wildlife and habitats, enhance quality of life, contribute to the integrity of the broader environment, increase property values, and augment a sense of belonging (Figure 17). Although the overall response to the question was quite positive from both types of communities, a small number of respondents from the sustainable communities were slightly strict to the statement about the role of green spaces serving local habitats, while some residents from 
the conventional communities took a neutral position on the role of green spaces as a component of increasing property value.
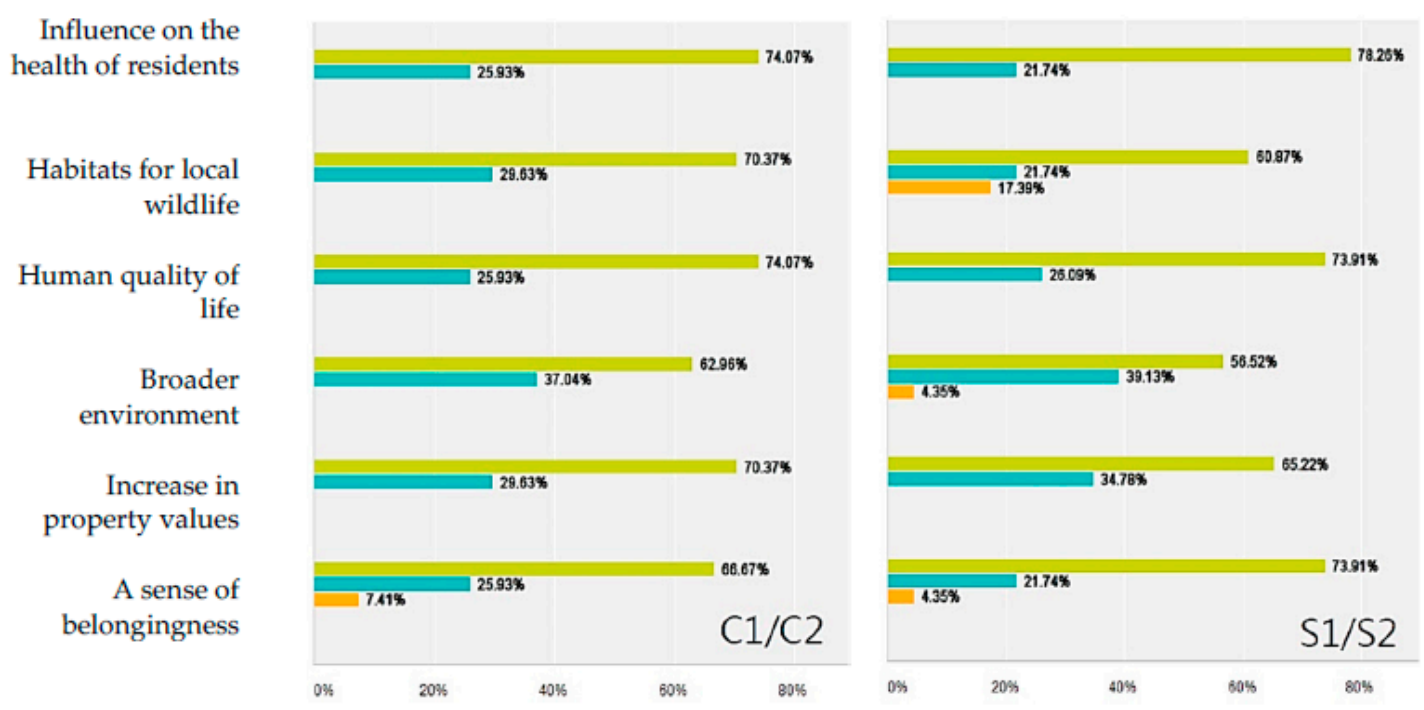

Figure 17. Residents' values for the roles and services of community green spaces (green: strongly agree; blue: agree; orange: neutral).

\section{- Preference and Landscape Demands}

With the availability of landscape features in each community, respondents were asked to select the existing natural elements they value the most. The perceived uniqueness was found in the landscape features such as lakes, mountains, growing trees, wildlife, and natural trails. On the other hand, community vegetable gardens were one of the features that were not available at the time in any of the communities but was the most wished for element in each of the four communities. Landscape demands from the conventional communities included groves for shade, benches for seating, paved paths, a neighborhood park with bathrooms, more spaces for entertaining, and grassy areas for children to play. Sustainable community respondents mentioned demands for more water features such as ponds and natural washes, neighborhood parks with native plants, xeriscaping, botanical garden, and more spaces for outdoor activities such as skateboard parks, bike paths, and campgrounds. Shading seemed important to all the communities in the hot and dry climate.

To the optional question for comments regarding structure, arrangement, and nature of community green spaces, a respondent indicated the functional importance of the green spaces by stating the following, "Green areas are very important; they are the perfect place for families to play and grow." Some people were quite conscious about the spatial and ecological aspects of the community green spaces. One person interviewed said, “. . . they're pretty well organized. However, I don't like the disconnectedness of green space." Another person stated that "individual community green spaces need to connect better with public infrastructure like bike lanes, city parks, and other communities surrounding." As to value-related questions, Dobson Ranch (C1) residents viewed lakes, trees, wildlife, paths, and front yard landscape as valuable natural characteristics in and around their community. Superstition Vistas (C2) residents valued the existence of adjacent mountains and overall landscape beauty. Verrado (S1) residents perceived water fountains, mountain desert, petroglyphs, natural trails, wildlife, and growing trees as a unique set of their community landscape elements. Las Sendas (S2) respondents expressed favor for mountains, natural trails, wildlife, and grass. During the in-depth additional interview followed by the questionnaire, some respondents living in the sustainable communities mentioned that the availability and quality of green spaces were the main factors of their moving choice. 


\section{Discussion and Conclusions}

This preliminary case study exhibits the variance between the physical green space connectivity and the areas of ecological significance. While the conventional communities demonstrate a moderate level of physical connectedness of the landscape features, the sustainable communities showed a large portion of landscapes with higher ecological potentials resulting, in part, from the site location and not-yet-built areas within the community boundaries. Through the questionnaire survey and brief follow-up interviews, it became evident that people desire to have quality green spaces and to interact with nature in and around the community. This can impact planning for community developments that are responsive to both human and ecological values and which are beneficial to ecological and environmental improvements at the site and city scales. There are some proven examples in which ecological elements were included in larger-scale planned community designs and were also liked by the public [20]. This lends a possibility to applying ecological processes of and human connections to nature into sensitive development for planned communities in many metropolitan areas.

While overall quality of community green spaces falls under the governance of individual Home Owner's Associations (HOAs) (primarily as a post-development control for landscape aesthetics and management), the ecological mechanisms manifested in the spatial arrangement and the amount and connectivity of the community green spaces need to be considered in the early stage of the community design and planning process. In fact, a study demonstrated home owners feel more 'natural' if there are more than just yards in their neighborhood although they perceive their yards as an ecological actor and starting place for communication about ecosystem functions [21].

The quality of life and human well-being are a frequently declared catch phrase for contemporary community development. As the residents' survey of this study implies, the general definition of 'livability' of a neighborhood condition that supports urban quality, safety, affordability, and civic involvement can be further extended to that of providing other sustainability benefits such as elevating green spaces' quality, exposures to and coexistence with urban wildlife, and the immediate experience with urban nature as everyday landscape opportunities. As such, a higher degree of resident satisfaction could be achieved with careful landscape planning as a means to support public goods and urban ecosystem services. Arguably, the composition, configuration, and functions of the green spaces which may not be marketable points can virtually increase residents' appreciation of the place they live and even influence a long-lasting stewardship for local ecosystems and community sustainability.

Although this study does not provide a causal relationship between landscape connectivity and perceived sustainability, the results from the connectivity analysis and residents' survey find a general correlation between them and emphasizes the unrecognized importance of physical and ecological connection to landscapes as a means to help balance out sustainability in modern communities. For the cases taken as sustainable communities in this study, there are significant amounts of land that have not been specified for any particular use yet within the community boundaries (Figure 18). Technically, the ratio of the privatization of vacant land parcels to non-privatized is reasonably higher in large-scale master-planned communities than in traditional neighborhoods. When considering the fact that the large-scale master-planned community is becoming a dominant type of residential development, there are bountiful opportunities for capitalizing upon the non-specified areas in a more ecologically sustainable manner (e.g., comprehensive conservation subdivision planning), rather than setting aside parcels for future piecemeal subdivisions. Especially in a huge metropolitan area in which the morphology interferes with urban ecology and biodiversity, preserving and maintaining the human communities' green spaces with ecological services is equally important as natural reserves outside the urban fringes. Like other big cities following such a developmental path, Phoenix is experiencing a typical urban sprawl with low urban densities. These continuous developments with less idiosyncratic landscape features will only produce cookie-cutter housing patterns contributing to another swath of sprawled land. One of the reasons that the Phoenix metro area struggles with the urban and suburban sprawl challenge has to do with the grid system, cheap land, and little or no land scrutinization for landscape cohesion and ecological values. Also, as single-family housing increases, lot sizes tend to 
be larger as well. The preservation of open and natural lands (even marginally) in the community plan boundary will be able to provide some potential sustainable benefits and opportunities that are otherwise lost in the community experience.

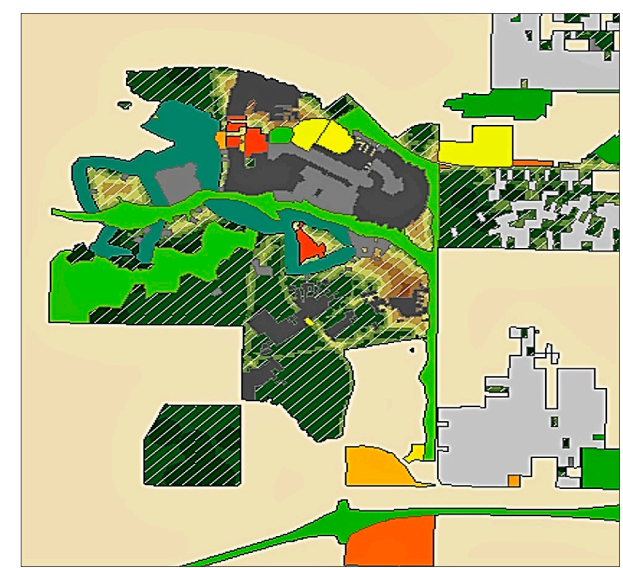

(a)

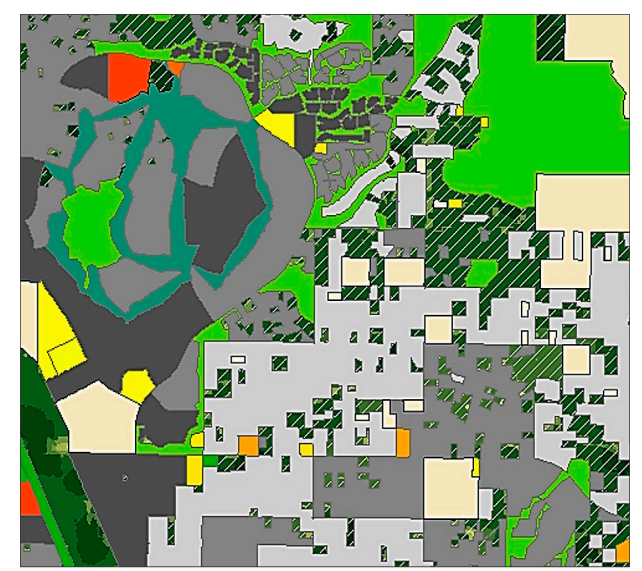

(b)

Figure 18. Vacant areas (hatched) overlaid with the high ecological connectivity areas (dark green areas). (a) Verrado; (b) Las Sendas.

Deliberate and careful urban design and planning that allows developers and planners to designate potential areas for connectivity conservation can increase the community capacity to afford added values of landscape and ecosystem services and will help serve to create true sustainable communities. Furthermore, the ecological enhancement of the community-scale landscapes will contribute to optimizing regional linkages of the broader ecological network. As Lynch [22] argues, understanding how to better connect our cities with the benefits nature provides will be increasingly important as people migrate to cities and flourish in them. Having and holding green spaces in proper locations within individual communities will help to bridge natural infrastructures within the human dominated landscapes. This will eventually be beneficial in dealing with emerging social, ecological, environmental, and aesthetic challenges of this expanding urban growth [23]. Neighborhood development per se inevitably reduces the availability of habitat structures in urban landscapes which can jeopardize urban ecological sustainability [24]. However, with the planning and utility of design tools such as ecological design, spatial zoning, and community engagement, the destruction of habitat structures can be minimized and the balance between socio-economic priorities and biodiversity conservation may become achievable even at the site scale when those strategies can be practically implemented in those individual neighborhoods.

Some limitations of this study include the constraints on generalizability inherent in the use of the non-probability sampling method. The online survey was responded to by the residents who were able to access the survey on community center websites and social media sites during the given survey time period and the in-person survey was bounded by author's time and workforce. There may be a potential response bias resulting from the demographic and socio-economic characteristics of the respondents as well. Also, the sample does not perfectly follow the pattern of the characteristics of the total population in terms of the shares of age composition and home ownership, although education characteristics, income level, and racial distribution show a similar pattern with the sample. The predominance of the female population in the sample was shown in the total population in a way but was not very significant ( 52 percent female in conventional communities and 51 percent in sustainable communities). In this respect, the residents' survey may not represent the whole population but represent the opinion of those active enough to take the survey. Nevertheless, this study reveals a cross section of the community green spaces in their use and perceived values for each type of chosen communities. 
This study suggests that the development of connective green space should be allocated a more central position in spatial planning and community development. Future planning and design efforts need to consider the quantity, quality, and connectivity of neighborhood landscapes based on fine grained analysis of site features and context, inherent and emergent functions of site-scale ecosystems, and spatial relationships with surrounding landscapes at various levels. In doing so, the use of local green infrastructure concepts and practices will be useful to foster community connections to ecological sustainability while promoting ecosystem and human health [25]. As Jerome [26] argues, community-scale green infrastructure and related voluntary activities could contribute to broader-scale ecological networks and the increase of 'interconnectivity' between sites of green infrastructure [27] and 'continuity' across 'hubs' (larger areas) and 'sites' (smaller areas) [28]. Generally, small scale green infrastructure integrated with urban and community development can become a significant mechanism for delivering multi-functional benefits attributed to green infrastructure.

The cumulative effects of such practices will bring greater ecosystem services into urban areas including: improving air quality, reducing storm water, mitigating urban heat island effects, and creating wildlife habitat [29-31]. Ecological and social benefits derived from community green spaces can offer the prospect of landscape and urban planning models with higher standards for landscape performance, which in turn contributes to increasing urban sustainability [13,32]. This research infers that green space connectivity helps humans relate to nature at the community scale. Ecologically sensitive community development should be considered to mitigate the impacts of the larger development of our human settlements on ecological processes in a nested hierarchy. This connective approach sets a helpful framework for reshaping our understanding and implementation of community sustainability and renewing community design and decision making practices that can promote ecological health and human well-being. The pursuit of these ecologically friendly alternatives to the mainstream community development prototypes may be one of the ways to re-write the infamy of the city as an ecological wasteland and turn the tide of community development toward a more sustainable and multiservice-oriented organism.

Conflicts of Interest: The authors declare no conflict of interest.

\section{References}

1. Byrne, J.; Wolch, J. Nature, race, and parks: Past research and future directions for geographic research. Prog. Hum. Geogr. 2009, 33, 743-765. [CrossRef]

2. Chiesura, A. The role of urban parks for the sustainable city. Landsc. Urban Plan. 2004, 68, 129-138. [CrossRef]

3. Ryan, R. Exploring the effects of environmental experience on attachment to urban natural areas. Environ. Behav. 2005, 37, 3-42. [CrossRef]

4. Alcock, I.; White, M.P.; Wheeler, B.W.; Fleming, L.E.; Depledge, M.H. Longitudinal effects on mental health of moving to greener and less green urban areas. Environ. Sci. Technol. 2014, 48, 1247-1255. [CrossRef] [PubMed]

5. Kuo, F.E.M. Parks and Other Green Enviroments: Essentail Componenets of a Healthy Human Habitat; National Recreation and Park Assocaition: Ashburn, VA, USA, 2010.

6. Maas, J.; Verheij, R.A.; Groenewegen, P.P.; Vries, S.D.; Spreeuwenberg, P. Green space, urbanity, and health: How strong is the relation? J. Epidemiol. Commun. Health 2006, 60, 587-592. [CrossRef] [PubMed]

7. Thompsona, C.W.; Roe, J.; Aspinall, P.; Mitchell, R.; Clowd, A.; Miller, D. More green space is linked to less stress in deprived communities: Evidence from salivary cortisol patterns. Landsc. Urban Plan. 2012, 105, 221-229. [CrossRef]

8. Wolch, J.R.; Byrne, J.; Newell, J.P. Urban green space, public health, and environmental justice: The challenge of making cities 'just green enough'. Landsc. Urban Plan. 2014, 125, 234-244. [CrossRef]

9. Farmer, M.C.; Wallace, M.C.; Shiroya, M. Bird diversity indicates ecolgoical value in urban home prices. Urban Ecosyst. 2013, 16, 131-144. [CrossRef] 
10. Martina, C.A.; Warren, P.S.; Kinzig, A.P. Neighborhood socioeconomic status is a useful predictor of perennial landscape vegetation in residential neighborhoods and embedded small parks of Phoenix, AZ. Landsc. Urban Plan. 2004, 69, 355-368. [CrossRef]

11. Wu, J. Urban ecology and sustainability: The state-of-the-science and future directions. Landsc. Urban Plan. 2014, 125, 209-221. [CrossRef]

12. Forman, R.T.T. Urban Rregions: Ecology and Planning Beyond the City; Cambridge University Press: Cambridge, MA, USA, 2008.

13. Forman, R.T.T. Urban Ecology: Science of Cities; Cambridge University Press: New York, NY, USA, 2014.

14. Newman, P.; Jennings, I. Cities as Sustainable Ecosystems: Principles and Practices; Island Press: Washington, DC, USA, 2012.

15. UK Government Web Archive. What Is a Sustainable Community? 2007. Available online: http:/ / webarchive. nationalarchives.gov.uk/20120919132719/http://www.communities.gov.uk/index.asp?id=1139866 (accessed on 20 December 2016).

16. Kong, L. Making sustainable creative/cultural space in Shanghai and Singapore. Geogr. Rev. 2009, 99, 1-22. [CrossRef]

17. Sustainable Communities Task Force. Appendix A: Definitions and Principles of Sustainable Communities. Sustainable Communities Task Force Report. 1997. Available online: http://clinton2.nara.gov/PCSD/ Publications/suscomm/suscoa.html (accessed on 19 December 2016).

18. Steiner, F. Frontiers in urban ecological design and planning research. Landsc. Urban Plan. 2014, 125, 304-311. [CrossRef]

19. Park, S. Ecological Connectivity Assessment and Urban Dimensions: A Case of Phoenix Metropolitan Landscape; Arizona State University: Tempe, AZ, USA, 2011.

20. Forsyth, A.; Crewe, K. Across the Board. Planning 2007, 73, 10-15.

21. Dahmus, M.E.; Nelson, K.C. Nature discourses in the residential yard in Minnesota. Landsc. Urban Plan. 2014, 125, 183-187. [CrossRef]

22. Lynch, A. Is it good to be green? Assessing the Ecological Results of County Green Infrastructure Planning? J. Plan. Educ. Res. 2016, 36, 90-104. [CrossRef]

23. Chawla, L. Benefits of Nature Contact for Children. J. Plan. Lit. 2015, 30, 433-452. [CrossRef]

24. Le Roux, D.S.; Ikin, K.; Lindenmayer, D.B.; Blanchard, W.; Manning, A.D.; Gibbons, P. Reduced availability of habitat structures in urban landscapes: Implications for policy and practice. Landsc. Urban Plan. 2014, 125, 57-64. [CrossRef]

25. Tzoulas, K.; Korpela, K.; Venn, S.; Ylipelkonen, V.; Kaźmierczak, A.; Niemela, J.; James, P. Promoting Ecosystem and Human Health in Urban Areas Using Green Infrastructure: A Literature Review. Landsc. Urban Plan. 2007, 81, 167-178. [CrossRef]

26. Jerome, G. Definining community-scale green infrastructure. Landsc. Res. 2017, 42, 223-229. [CrossRef]

27. Benedict, M.A.; McMahon, E.T.; Fund, T.C. Green Infrastructure [Electronic Book: Linking Landscapes and Communities; Island Press: Washington, DC, USA, 2006.

28. Ahern, J. Green Infrastructure for Cities: The Spatial Dimension; IWA Publishing: London, UK, 2007.

29. Ahern, J.; Cilliers, S.; Niemelä, J. The concept of ecosystem services in adaptive urban planning and design: A framework for supporting innovation. Landsc. Urban Plan. 2014, 125, 254-259. [CrossRef]

30. TEEB. TEEB Manual for Cities: Ecosystem Services in Urban Management. 2011. Available online: http:/ / www.teebweb.org/wp-content/uploads/Study\%20and\%20Reports/Additional\%20Reports / Manual\%20for\%20Cities/TEEB\%20Manual\%20for\%20Cities_English.pdf (accessed on 18 December 2016).

31. Haase, D.; Frantzeskaki, N.; Elmqvist, T. Ecosystem Services in Urban Landscapes: Practical Applications and Governance Implications. Ambio 2014, 43, 407-412. [CrossRef] [PubMed]

32. Bolund, P.; Hunhammar, S. Ecosystem services in urban areas. Ecol. Econ. 1999, 29, 293-301. [CrossRef]

(C) 2017 by the author. Licensee MDPI, Basel, Switzerland. This article is an open access article distributed under the terms and conditions of the Creative Commons Attribution (CC BY) license (http:/ / creativecommons.org/licenses/by/4.0/). 